\title{
Educação sexual no contexto escolar: vozes de professores do Ensino Fundamental
}

\author{
Sex education in the school context: voices of elementary School Teachers \\ La educación sexual en el contexto escolar: voces de maestros de Escuela Primaria
}

Recebido: 12/02/2022 | Revisado: 19/02/2022 | Aceito: 21/02/2022 | Publicado: 03/03/2022

\author{
Lizandra Martins Soares \\ ORCID: https://orcid.org/0000-0002-4887-3439 \\ Universidade de Integração Latino-Americana, Brasil \\ E-mail: lizandrasooares@gmail.com \\ Nandra Martins Soares \\ ORCID: https://orcid.org/0000-0002-0224-9083 \\ Centro Universitário Dinâmica das Cataratas, Brasil \\ E-mail: nandrasoares@yahoo.com.br
}

\begin{abstract}
Resumo
A Educação Sexual está nos Parâmetros Curriculares Nacionais (PCNs), e propõe que ao ministrar sobre a educação sexual se busque informar e problematizar as questões referentes à sexualidade a partir da vivência, das crenças e dos valores dos educandos, para ampliar as informações e assim levantar questionamentos acerca das escolhas mais adequadas para cada um. Porém, para se alcançar esse objetivo, é necessário que o professor esteja preparado para tal temática e para as devidas situações que podem surgir em sala de aula com seus alunos. Portanto, o objetivo desse trabalho foi compreender as percepções do professor acerca da educação sexual, bem como os desafios e facilidades decorrentes do contexto escolar. A pesquisa foi desenvolvida em duas escolas do município Foz do Iguaçu - PR, e a coleta de dados se deu através de uma entrevista semiestruturada realizada com seis professores que se disponibilizaram voluntariamente em participar da pesquisa. Os resultados demonstram que existe uma grande lacuna no trabalho a respeito da educação sexual e carece de formação para os professores, gerando medo e insegurança ao falar sobre sexualidade, e ainda faltam materiais didáticos de apoio sobre o tema, para facilitar o estudo e tornar a aprendizagem interativa e dinâmica. Com isso é possível entender que a proposta do PCNs não contempla a realidade estudada, então sugere-se novos olhares acerca da legislação e prática para que de fato se consolide uma educação sexual pautada na humanidade e em informações que instrumentalizem e forneçam segurança ao professor ao abordar o assunto.
\end{abstract}

Palavras-chave: Sexualidade; Escola; Docente; Percepção.

\begin{abstract}
Sexual Education is in the National Curriculum Parameters (PCNs), and proposes that when ministering on sexual education, one seeks to inform and problematize issues related to sexuality from the experience, beliefs and values of the students, to expand the information and thus raise questions about the most appropriate choices for each one. However, in order to achieve this objective, it is necessary that the teacher is prepared for this theme and for the appropriate situations that may arise in the classroom with their students. Therefore, the objective of this work was to understand the teacher's perceptions about sex education, as well as the challenges and facilities arising from the school context. The research was carried out in two schools in the municipality of Foz do Iguaçu - PR, and data collection took place through a semi-structured interview with six teachers who voluntarily volunteered to participate in the research. The results show that there is a large gap in the work on sex education and there is a lack of training for teachers, generating fear and insecurity when talking about sexuality, and there is still a lack of didactic support materials on the subject, to facilitate the study and make the interactive and dynamic learning. With this, it is possible to understand that the PCNs proposal does not contemplate the reality studied, so new perspectives on legislation and practice are suggested so that in fact, a sex education based on humanity and information that instrumentalizes and provide security for the teacher to the address the matter.
\end{abstract}

Keywords: Sexuality; School; Teacher; Perception.

\section{Resumen}

La Educación Sexual se encuentra en los Parámetros Curriculares Nacionales (PCN), y propone que al ministrar sobre educación sexual se busque informar y problematizar temas relacionados con la sexualidad desde la experiencia, creencias y valores de los estudiantes, para ampliar la información y así plantee preguntas sobre las opciones más apropiadas para cada uno. Sin embargo, para lograr este objetivo, es necesario que el docente esté preparado para este tema y para las situaciones adecuadas que se puedan presentar en el aula con sus alumnos. Por lo tanto, el objetivo de este trabajo fue comprender las percepciones de los docentes sobre la educación sexual, así como los desafíos y facilidades que surgen del contexto escolar. La investigación se llevó a cabo en dos escuelas del municipio de Foz do 
Iguaçu - PR, y la recolección de datos ocurrió a través de una entrevista semiestructurada con seis profesores que voluntariamente se ofrecieron a participar en la investigación. Los resultados muestran que existe un gran vacío en el trabajo sobre educación sexual y falta formación de los docentes, generando miedo e inseguridad al hablar de sexualidad, y aún faltan materiales de apoyo didáctico sobre el tema, que faciliten la el estudio y hacer el aprendizaje interactivo y dinámico. Con esto, es posible comprender que la propuesta de las PCN no contempla la realidad estudiada, por lo que se sugieren nuevas perspectivas de legislación y práctica para que en los hechos, una educación sexual basada en la humanidad y la información que instrumentalice y brinde seguridad al docente para la dirección del asunto.

Palabras clave: Sexualidad; Escuela; Docente; Percepción.

\section{Introdução}

A Educação Sexual é um dos temas transversais propostos nos Parâmetros Curriculares Nacionais do Ministério de Educação e Cultura, no entanto, os assuntos relacionados à sexualidade ainda trazem muitos questionamentos ao professor e muitas vezes podem resultar no educador um sentimento de desconhecimento e impotência ao se deparar com esse tema (Schindhelm, 2011).

A sexualidade infantil no contexto escolar é um grande desafio para educadores, pais e principalmente para a criança, que ao se desenvolver tem curiosidade sobre as mudanças que vão ocorrendo ao longo da vida. A sexualidade é compreendida por muitos como um assunto polêmico e complexo para ser discutido na escola, devido as diferentes visões, culturas, tabus e valores que estão impostos neste contexto (Schindhelm, 2011).

Ter a sexualidade como um conteúdo a ser aprendido e entendido pelos alunos pode remeter aos educadores uma sensação de despreparo para encarar as dúvidas relacionadas a esse tema na rotina escolar. É nesse ambiente repleto de questionamentos que a escola precisa entender qual seu papel e oferecer suporte aos docentes, pois em muitos casos, essa falta de posicionamento resulta em sentimentos de angústia, constrangimento e fracasso (Foucault, 1977).

Nossos jovens estão tendo acesso a informações a respeito da sexualidade desde cedo e muitos iniciam sua vida sexual sem maturidade e conhecimento para tal. A estimulação precoce a qual crianças e adolescentes estão expostos pela mídia, que propaga o sexo e o erotismo, favorece a curiosidade sexual, a busca de informações sobre sexualidade e a prática de experiências sexuais. Isso exige cuidados por parte de pais e profissionais devido às vulnerabilidades relacionadas à precocidade da iniciação sexual, expondo os jovens a riscos, como doenças sexualmente transmissíveis, gravidez indesejada e desajustes emocionais decorrentes, por isso, a importância da orientação aos alunos, fazendo com eles reflitam e utilizem seus conhecimentos para a sua própria proteção.

A escola é a instituição mediadora entre o aluno e o mundo. É pelo conhecimento adquirido através dos professores que a criança aprende, se desenvolve e se prepara para encarar muitas adversidades e desafios da sociedade. A partir disso é importante a escola entender que a sexualidade e o desenvolvimento humano são questões indissociáveis e o desenvolvimento e curiosidades acerca desse tema permeiam a infância e a adolescência (Schindhelm, 2011).

Nesse sentido a presente pesquisa traz como objetivo compreender as percepções do professor acerca da educação sexual, bem como os desafios e facilidades decorrentes do contexto escolar.

\section{História da Educação Sexual na escola}

Em meados do ano de 1928, foi discutida no Congresso Nacional a aprovação de Programa de Educação Sexual para educadores para se trabalhar com crianças acima de 11 anos, sendo algo central nos projetos de educação sexual (Aquino \& Martelli, 2012).

Somente a partir de 1930 que o Colégio Batista do Rio de Janeiro apresentou em seu currículo o ensino de evolução das espécies e educação sexual, tendo como caráter inicial a reprodução feminina. A partir do ano de 1935 foram incluídas 
discussões e análises da reprodução masculina, tendo como idealizador o professor Stawiarski, que foi processado, resultando na sua demissão (Guimarães, 1995).

Já nos anos de 40 e 50 não se tem conhecimento de trabalhos realizados sobre a educação sexual, sendo que nessa época a Igreja Católica reprendia assuntos em questão, possuindo total domínio ao sistema educacional, mas mesmo assim foram publicados livros sobre a temática, mas dentro da moral católica, enfatizando uma educação de responsabilidade paternal, mas também com intuito de responder questões de caráter biológico e reprodutiva, fomenta Guimarães, 1995.

Segundo Guimarães (1995), na década de 60 surgiram várias tentativas para a implementação de educação sexual nas escolas públicas e particulares, mas devido às mudanças políticas geradas pelo Golpe Militar de 1964, esses programas tiveram que ser interrompidos, devido à repressão do moralismo vigente, isso porque a igreja católica ainda possuía o domínio ao sistema educacional.

De acordo com César (2009), somente a partir dos anos finais da década de 70 e anos 80 que a sociedade brasileira conviveu a abertura política, ocorrendo grandes mudanças, inclusive sociais, mas principalmente no campo da sexualidade, obtendo-se novas concepções de compreender a educação sexual.

Contudo, seguindo esse contexto, observa-se que com o passar do tempo às questões relacionadas à sexualidade tiveram algumas conquistas, mas também recuou em alguns momentos, e percebe-se que quando se tratava da temática, a tomada de decisões na maioria das vezes ficava por conta da política e da igreja na época. Apesar de atualmente se falar muito de sexo, ele continua sendo um assunto delicado por existir inúmeras barreiras que reprimem o assunto, família, sociedade, religião e até mesmo a escola.

\subsection{Transversalidade: Orientação sexual na educação}

A discussão sobre o tema "sexualidade" na escola se encontra atualmente ligada aos Parâmetros Curriculares Nacionais (PCNs) criados pelo Ministério da Educação do Brasil no final do século passado. Sob o título de "Orientação Sexual" um dos temas transversais associados a "questões sociais urgentes" (Brasil, 1998, p.65), os PCNs enfatizaram a atenção à sexualidade por conta da "grande importância no desenvolvimento e na vida psíquica das pessoas, pois além da sua potencialidade reprodutiva, relaciona-se com a busca do prazer, necessidade fundamental das pessoas" (Brasil, 1998, p.295). Entendendo que a exposição de conteúdos relacionados à reprodução humana era insuficiente para a exploração do assunto, os PCNs sugeriam uma abordagem de forma transversal, contemplando assim as diversas áreas de conhecimento que representam as disciplinas escolares.

Os PCNs por sua vez, revelavam em suas entrelinhas a complexidade da temática sexualidade. A conduta sexual humana não era apenas uma atividade de foro íntimo, como pode parecer à primeira vista: à coletividade social se devem questões como a natalidade, crescimento demográfico, viabilidade dos descendentes e também doenças associadas à transmissão pelo sexo, elementos que configuram a discussão quando se trata de saúde pública. A gravidez na adolescência era encarada como um foco de investimento político que visava a administração do comportamento sexual jovem, situação que põe a escola no meio de interesses que extrapolam as questões acadêmicas tradicionalmente atribuídas a si (Altmann, 2003).

À revelia destas considerações, entretanto, é comum vermos delegada à escola uma expectativa ingênua sobre seu papel. Espera-se desta instituição a formação de indivíduos autodisciplinados e que realizem suas iniciações no sexo sem trazer problemas decorrentes que além da gravidez indesejada e da proliferação de doenças, mas hoje um fato de grande importância o reconhecimento como indivíduo que engloba as questões de gênero e orientação sexual, como se a escolarização fosse uma solução simples para todo esse processo de descobrimento do corpo e sua inserção no mundo.

A abordagem da temática sexualidade na escola geralmente fica a cargo dos professores de Ciências e Biologia, que na maioria das vezes é realizada através de uma perspectiva biologicamente diferente daquela sugerida pelos PCNs e 
pesquisadores do tema, concentrando atenções em características anatômicas e fisiológicas dos aparelhos reprodutivo masculino e feminino (Altmann, 2003; Jardim \& Brêtas, 2006 \& Maistro 2006). Conquanto, alguns pesquisadores apontam para problemas envolvendo a formação docente e/ou a maneira como o sexo é estruturado no currículo das ciências naturais, contribuindo para isso a tendência observada nos livros didáticos em apresentá-lo com foco principal em características biológicas da reprodução (Altmann, 2003). Outros pesquisadores também enfatizam problemas particulares dos docentes, como resistência ou dificuldade pessoal na abordagem do assunto (Jardim \& Brêtas, 2006). Por outro lado, a pressão de pais ou outros membros da comunidade escolar também são frequentes, uma vez que a discussão sobre sexualidade está ligada de maneira inevitável a questões de preconceito, religião e tudo o que envolve a temática sexualidade, fazendo de tensões e conflitos um lugar comum na discussão sobre comportamento sexual na escola (Maistro, 2006).

\subsection{Práticas de Educação Sexual no contexto escolar}

De acordo com Beraldo (2003), falar de educação sexual nas escolas ainda gera bastantes polêmicas, que se associam inconvenientes e impróprias, pois a comunicação sobre esses assuntos ainda continua sendo um grande tabu, até por que no convívio familiar, muitos pais sentem-se desconfortáveis para falar abertamente com seus filhos e dar-lhes uma orientação adequada.

A escola quer queira, quer não, possui um papel muito importante para diminuir as consequências da falta de informação sobre educação sexual, pois as manifestações estão presentes e cabe ao professor problematiza-las, ou seja, questionar, dialogar elementos a respeito da temática, contribuindo para o desenvolvimento humano (Aquino \& Martelli, 2012).

De acordo com Braga (2006), é necessário que haja um diálogo no ambiente escolar em que se desperte a curiosidade e principalmente o interesse dos alunos, em se conhecer, sem preconceitos, pois esses assuntos são trazidos para dentro da escola junto com cada indivíduo e é necessário o desenvolvimento de uma ação reflexiva e educativa ao se tratar do assunto em questão.

Diante das interpretações de como trabalhar o tema, descreve-se que o professor precisa estar ciente que as questões referentes à sexualidade podem surgir em diferentes momentos em sala de aula, mesmo se já haviam sido trabalhadas pelo professor, faz-se necessário uma retomada (Quirino, 2003).

Dessa forma, diante da importância de se trabalhar o tema em sala de aula, cabe destacar que a prática docente na educação sexual ajuda os alunos a obter mais conhecimento sobre a sexualidade e também as vulnerabilidades existentes nessa fase do desenvolvimento. Porém os professores enfrentam muitas dificuldades na forma de abordagem da temática devido ao déficit na formação e o receio de serem mal interpretados pelos pais, portanto o diálogo surge como uma maneira de minimizar as dificuldades e fazer uma ponte entre a escola e as famílias com o objetivo de discutir a importância de se trabalhar a educação sexual no contexto escolar (Burchard et al.,2020).

Para Gaspar (2006), é essencial um trabalho conjunto da família e da escola no processo de educação sexual dos adolescentes a fim de esclarecer para os jovens suas dúvidas para que desfrutem da sua sexualidade saudavelmente e com responsabilidade. A escola sozinha não resolve a questão, descreve Paula e Santos (2012), sendo necessário que a família faça sua parte, mostrando aos jovens as questões de valores morais que cabe somente a ela.

\subsection{Educação sexual e a formação de professores}

A sexualidade humana, hoje muito discutida e colocada em pauta nas questões educacionais, está envolvida num contexto social de crenças, representações, valores, comportamentos, relações e identidades que são construídas e ao passar do tempo vem sendo reformuladas de acordo com o avanço da sociedade e com o desenvolvimento de ideias e pensamentos das 
pessoas.

Portanto, como já mencionado neste mesmo trabalho, parte-se do pressuposto que a escola é considerada o local para a estruturação da sexualidade completa e diferenciada, porém sabendo que a contextualização da temática ainda permanece marginalizada no currículo escolar.

(...) a escola é o espaço também de crítica sobre a sexualidade estabelecida e o laboratório das novas significações e vivências, não de uma maneira superficial como vem sendo feita, empirista, biologista, informativa e outra vez diretiva. Muitas escolas acreditam que fazem "educação sexual" por permitir que um padre ou um médico uma vez por ano fale sobre "sexo e amor", "métodos contraceptivos e aborto", "aparelhos reprodutor masculino e feminino" (Nunes, 1997, p.17).

Nesse sentido, constata-se que trabalhar a temática não é uma tarefa fácil para os professores, pois vai muito além do conteúdo e do diálogo em sala de aula, pois envolve questões morais que estão ligadas ao comportamento, costumes culturais e sociais que envolvem família e sociedade, e também tem um forte laço com a religiosidade, levando em consideração as crenças de cada um.

Figueró (2009) afirma que os professores sempre educam sexualmente seus alunos, mesmo que não tenham consciência, por meio da forma de como lidam com as situações do dia a dia. Nóvoa (2009) explicita que “ensinamos aquilo que somos e que, naquilo que somos se encontra muito daquilo que ensinamos". O professor dentro da sala de aula se torna, portanto, o "espelho" de seus alunos, e com sua postura contribui para que o aluno forme uma imagem positiva ou negativa do corpo, da sexualidade e do comportamento sexual.

Nesse sentido, Nóvoa (2018) afirma que o bom professor busca estratégias e possibilidades de ensino e aprendizagem, tentando fazer a diferença em prol de uma boa educação.

Podem inventar tecnologias, serviços, programas, máquinas diversas, umas a distância, outras menos, mas nada substitui um bom professor. Nada substitui o bom senso, a capacidade de incentivo e de motivação que só os bons professores conseguem despertar. Nada substitui o encontro humano, a importância do diálogo, a vontade de aprender que só os bons professores conseguem promover. É necessário que tenhamos professores reconhecidos e prestigiados; competentes, e que sejam apoiados no seu trabalho, o apoio da aldeia toda. Isto é, o apoio de toda a sociedade. São esses professores que fazem a diferença. É necessário que eles sejam pessoas de corpo inteiro, que sejam profissionais de corpo inteiro, capazes de se mobilizarem, de mobilizarem seus colegas e mobilizarem a sociedade, apesar de todas as dificuldades. (Novoa, 2018, p.18)

Sendo assim, um aspecto limitante com relação à formação de professores está diretamente interligado com a mobilização para a temática. Essa questão ainda permanece como opção pessoal, ou seja, se o professor sente a necessidade de trabalhar e tem interesse no tema, se se propõe a discutir ou não, atingindo as expectativas dos alunos em não apenas discutir questões biológicas, mas também suprir as curiosidades, angústias e expectativas a respeito do assunto. Para isso, é necessário construir e instrumentalizar professores com habilidades essenciais, proporcionando a eles condições de ampliar e reciclar seu conhecimento por meio de programas de atualização e capacitação direcionados a sexualidade.

A possibilidade de uma formação continuada nesta temática deve avançar, pois na maioria dos cursos de formação inicial, sejam da saúde ou da educação, não estão contempladas discussões que mostrem quem são os sujeitos que serão apresentados a nós no cotidiano do nosso trabalho e nem de como deveremos abordá-los (Rodrigues \& Salles, 2011, p.3)

Dessa forma, é muito importante as universidades investirem na formação dos profissionais do magistério, inclusive os da educação superior que não foram formados e nem preparados para trabalhar com tal tema.

No mesmo sentido, a formação inicial dos professores tem deixado a desejar quando se trata de educação sexual e 
também em uma formação continuada, para que os professores possam abordar a temática com segurança, visto que a insegurança é um dos empecilhos que dificulta o diálogo abertamente com os alunos.

\section{Metodologia}

O presente trabalho trata-se de uma pesquisa de finalidade aplicada, de abordagem qualitativa, de caráter descritivo e exploratório, desenvolvida por meio de pesquisa de campo e de maneira transversal. A pesquisa qualitativa é descrita por Minayo (1994) como um nível de realidade que não pode ser quantificado e trabalha com o universo de significados, motivos, aspirações, crenças, valores e atitudes que não podem ser reduzidos à operacionalização de variáveis.

A pesquisa foco deste estudo foi realizada com seis professores do Ensino Fundamental de duas escolas públicas do munícipio de Foz do Iguaçu - PR. Primeiramente foi realizado um sorteio entre as 51 escolas do município e após a seleção das duas escolas a pesquisa foi apresentada aos professores e a amostra foi selecionada a partir do interesse voluntário dos mesmos em participar.

Para a coleta de dados foi elaborado um roteiro de entrevista semiestruturada, abordando assuntos acerca da dificuldade e formação dos professores sobre práticas de educação sexual, existência de materiais didáticos para essa prática e questões sobre a percepção do professor sobre a importância do tema ser abordado na escola. A entrevista foi realizada por meio da plataforma Meet, tendo em vista, o momento pandêmico em que ainda vivemos, devido ao Coronavírus.

A pesquisa foi realizada mediante contato prévio com a coordenação das escolas, após o sorteio, para iniciar a divulgação da pesquisa. Posteriormente as entrevistas foram agendadas de acordo com a disponibilidade dos 6 participantes, com assinatura e concordância prévia ao Termo de Consentimento Livre e Esclarecido, o qual foi encaminhado no e-mail dos participantes.

Com as devidas autorizações de todos os envolvidos, foi aplicado o roteiro de entrevista, na qual as respostas foram gravadas para posterior transcrição e análise.

Os dados foram analisados por meio da Análise de Conteúdo, que é caraterizada como "um conjunto de técnicas de análise de comunicação que visa obter, por procedimentos sistemáticos e objetivos de descrição do conteúdo das mensagens, indicadores que permitam a inferência de conhecimentos relativos às condições de produção/recepção destas mensagens" (Bardin, 2011, p.229).

Ressalta-se que a pesquisa foi aprovada pelo Comitê de Ética em Pesquisas com Seres Humanos, de acordo com o CAAE 95870418.3.0000.8527 e somente após isto teve início a coleta de dados.

\section{Resultados e Discussão}

A fim de apresentar os participantes da pesquisa de modo mais detalhado, o Quadro 1 descreve algumas características dos seis professores. 
Quadro 1: Dados gerais dos professores entrevistados

\begin{tabular}{|c|c|c|l|}
\hline Professor & Idade & Tempo de docência & \multicolumn{1}{|c|}{ Formação } \\
\hline A & 53 anos & 28 anos & $\begin{array}{l}\text { Graduação em Pedagogia e Licenciatura plena em } \\
\text { Matemática. }\end{array}$ \\
\hline B & 45 anos & 19 anos & $\begin{array}{l}\text { Curso Magistério, Graduação em Pedagogia, Pós - } \\
\text { Graduação em interdisciplinaridade. }\end{array}$ \\
\hline C & 34 anos & 3 anos & $\begin{array}{l}\text { Graduação em Pedagogia, Pós - Graduação em Gestão } \\
\text { Pública e em Psicopedagogia }\end{array}$ \\
\hline D & 32 anos & 7 anos e 8 meses & $\begin{array}{l}\text { Graduação em Pedagogia, Especialização em metodologia } \\
\text { para o ensino de Biologia e Química. }\end{array}$ \\
\hline E & 47 anos & 10 anos & Graduação em Pedagogia. \\
\hline F & 41 anos & 6 anos & Graduação em Pedagogia. \\
\hline
\end{tabular}

Fonte: Autores (2021).

É possível perceber que os professores, na grande maioria, está há bastante tempo na prática docente, com o mínimo de 3 anos e máximo de 28 anos, no entanto ao questionar sobre a formação, nenhum relatou cursos, formações ou até mesmo especializações em que o tema "educação sexual” foi abordado. O que nos permite inferir a escassez de capacitações nesta área e também a pouca procura pelos professores.

Contudo, a partir da análise das entrevistas foram elencadas duas categorias para serem discutidas ao longo do trabalho, que são: categoria 1: Importância do tema sexualidade na formação de professores e categoria 2: Dificuldades e desafios para trabalhar o tema sexualidade na escola.

\section{Categoria 1: Importância do tema Sexualidade na formação dos professores}

A escola hoje é vista como um espaço de socialização e é nela que as crianças e adolescentes passam maior parte do seu tempo, tendo seu primeiro contato e estabelecendo diversos tipos de relações, sejam elas afetivas e sociais, fora do âmbito familiar. É também na escola que surgem momentos de discussão sobre assuntos importantes para a formação dos alunos, dentre eles estão as questões ligadas à sexualidade. Essa tarefa, que geralmente é dada aos professores, nem sempre é uma tarefa fácil, pois ainda existem muitos tabus sobre a temática e os docentes podem não ter uma preparação inicial para trabalhar e discutir com os alunos sobre a educação sexual em sala de aula.

Silva e Santos (2011) ao fazer uma revisão em seus estudos, concluem que existe uma lacuna na formação inicial docente, pois no currículo regular do curso de licenciatura não existe um espaço para a reflexão com os futuros professores sobre a sexualidade, fazendo com que o trabalho teórico e prático a respeito da temática não fique bem fundamentado. Essa reflexão feita pelos autores vai de encontro com alguns relatos feitos pelas professoras entrevistadas nesse estudo. Quando lhes foi questionado se na sua formação inicial elas tiveram alguma disciplina ou capacitação que abordou como trabalhar a educação sexual com os alunos, responderam:

"Não, isso tudo eu fui aprendendo com o passar do tempo, procurando conversar com médicos. Teve alguns cursos que era para prevenção de AIDS, onde se conversava e trocava ideias com professores de outras escolas, de outras cidades, mas o que me ensinou no começo a falar e a tratar desse assunto foi quando eu conversei com o médico." (Professora A)

"Não, e acredito que deveria ter, pois só vamos sentir dificuldades quando formos para a sala de aula trabalhar esse tema." (Professora E)

"Não, nada, mas eu gostaria de ter essa formação, por mais que hoje as crianças estejam mais desenvolvidas é muito difícil trabalhar essas questões em sala de aula. Eu fico insegura de quais termos devo usar, achando que se eu falar os termos corretos talvez eles não entendam. Sempre procuro ter cuidado no que falo, por ter muitas questões 
relacionadas como família. Muitas vezes os pais acham que estamos incentivando seus filhos a iniciar, por exemplo, a vida sexual, então seria importante uma capacitação para sabermos lidar com isso." (Professora F)

A educação sexual vem sendo reconhecida pelos professores como um tema importante e necessário para o processo formativo pessoal e social dos alunos. Muitos deles se preocupam e se sentem, em vários momentos, inseguros e temerosos diante dessa tarefa (Figueiró, 2009).

Uma das grandes dúvidas que leva os professores a "não saber" como tratar do assunto, é a questão da idade dos alunos, em qual idade ou em qual ano a educação sexual deveria começar. Essa foi uma discussão levantada nesta pesquisa, onde dentre os professores entrevistados, $70 \%$ responderam que deveriam começar a trabalhar ações de educação sexual no $5^{\circ}$ ano, os demais acreditam que deveria começar no $6^{\circ}$ ou $7^{\circ}$ ano. Isso mostra que os docentes não têm certeza de quando seria o momento certo para trabalhar a sexualidade na escola.

Nesse sentido, Jardim e Brêtas (2006) abordam que diante da necessidade de atingir expectativas dos alunos de discutir não só questões biológicas faz-se necessário abordar questões que envolvem sentimentos, valores, moral e ética, é necessário construir e instrumentalizar professores com habilidades essenciais, proporcionando a eles condições de ampliar e reciclar seu conhecimento por meio de programas de atualização e capacitação direcionados a sexualidade.

A possibilidade de uma formação continuada nesta temática deve avançar, pois na maioria dos cursos da formação inicial, sejam da saúde ou da educação, não estão contempladas discussões que mostrem quem são os sujeitos de direitos que serão apresentados a nós no cotidiano do nosso trabalho e nem como deveremos abordá-los (Rodrigues \& Salles, 2011, p. 3).

Nesse contexto, a educação sexual aliada à formação de professores contribui para aprimorar a prática docente na escola, fazendo com que haja uma relação onde todos possam sair beneficiados, professores, estudantes e familiares. Os estudos dos autores anteriormente citados comtemplam questões que foram discutidas na pesquisa desse trabalho, onde as professoras entrevistadas falaram da importância de uma formação continuada sobre a temática educação sexual.

Seria muito importante uma formação continuada, porque, por incrível que pareça, ainda temos colegas professoras que se apavoram com certas coisas que ouvem na sala de aula ou com certas perguntas que alguns alunos fazem. (Professora A)

Com certeza, seria importante para sabermos como trabalhar a educação sexual, enriquecer a nossa prática em diferentes faixas etárias, principalmente com os pequenos, alunos de $4^{\circ}$ e $5^{\circ}$ ano, onde acredito ser à base de tudo. (Professora B).

Sim, com certeza, assim teríamos mais meios, formas e ideias de explicar o tema em sala de aula. (Professora D).

Com toda certeza, isso ajudaria muito a lidar com diversas situações, seria uma preparação para encarar a sala de aula. (Professora E).

Tendo como base essas lacunas encontradas na educação quando se trata da temática sexualidade, do déficit quanto a preparação e a formação dos professores no momento da abordagem do referido assunto em sala de aula com os alunos foi realizada uma leitura de diversos documentos para compreender como as políticas educacionais asseguram a temática da sexualidade na organização curricular nas escolas.

Como ponto de partida, os PCNs oferecidos pelo MEC, que atualmente estão em desuso, mas que são importantes como proposta inicial, para inserir a orientação sexual como tema transversal na educação (Brasil, 1998).

A Base Nacional Comum Curricular -BNCC (2016) é uma exigência colocada para o sistema educacional brasileiro e tem por finalidade orientar os sistemas para uma elaboração ativa de suas propostas curriculares e tem como objetivo apontar 
aquilo que todo o estudante brasileiro precisa aprender desde a Educação Infantil até o Ensino Médio.

A BNCC (2016) defende a ampliação dos conhecimentos conceituais, enfatizando a importância de que os jovens sejam bem informados, para que saibam se posicionar e tomar decisões acerca das questões que surgem no mundo atual. Garantem os conhecimentos referentes às diversas áreas, traçando objetivos e métodos próprios para cada disciplina, dentre eles, a sexualidade. Na BNCC do Ensino Fundamental, a temática está locada na disciplina de Ciências do $8^{\circ}$ ano, abordando questões como: transformações corporais, atuação dos hormônios sexuais, métodos contraceptivos, DSTs. Essa inserção no currículo das escolas aproxima os jovens de forma adequada às informações e às demais discussões acerca desse tema. No entanto não há referências para anos anteriores do ensino fundamental.

Portanto, os professores necessitam de uma formação contínua, buscando cada vez mais conhecimento e estratégias para trabalhar sexualidade com seus alunos, promovendo uma melhoria na qualidade de vida dos discentes, não somente em ambiente escolar, mas sim no dia a dia e inclusive no decorrer da vida adulta, por conta disso a formação continuada se torna fundamental na abordagem da temática (Santos, Assis, Marra \& Oliveira, 2021).

\section{Categoria 2: Dificuldades e desafios para trabalhar o tema Sexualidade na escola}

Um foco relevante neste trabalho foi avaliar como os professores se sentem ao falar com seus alunos em sala de aula sobre sexualidade, de que forma tentam abordar o tema, o que é mais difícil e quais as barreiras encontradas tanto na escola quanto na família.

$\mathrm{Na}$ entrevista a professora B, relata que: “[...] tratar da sexualidade é algo delicado, tenho medo de ir além, de avançar o sinal, pelo fato de ter alunos que acompanham meu raciocínio, outros não vão entender o que estou falando e acabo não saindo do corpo humano, mas acredito que sexualidade vai muito além disso, questões de relacionamento, afetividade... tem muitas coisas para se trabalhar, coisas do dia a dia, questões de convivência. Vamos pegar um exemplo que acontece muito, desde uma menina que vêm com o "short" muito curto, eles observam, cochicham entre eles, riem, daí aproveito essas oportunidades e abordo algumas questões que acho relevante a respeito da orientação sexual também, que mesmo crianças, percebemos que já tem muito preconceito quanto a isso, nesses casos trabalho com diálogo, com o objetivo de aceitação e tudo mais."

Outro ponto destacado nesse estudo foi a religião que se apresenta de maneira bastante forte na sociedade e que acaba restringindo as ações realizadas pelos professores em sala de aula sobre a temática, pois a religião tem para os seres humanos uma importância significativa. Seja qual for a crença, não podemos ignorar que ela tem exercido grande influência sobre o comportamento e consequentemente sobre a sexualidade. Com isso, os profissionais que tem a missão de falar da educação sexual com seus alunos, acabam tendo uma certa insegurança ao tratar sobre o assunto. Essa foi mais uma das barreiras citadas pelas professoras entrevistadas.

[...] temos a questão religiosa, nós aqui temos um grupo bem forte. Dependendo do que falo em sala de aula, posso ser mal interpretada, de estar "incentivando" o sexo, a sociedade aqui ainda não é "cabeça aberta" (Professora B)

[...] ainda temos famílias muito conservadoras, acho que depende muito do estilo de vida, da forma como foram criados, não sei, mas passam isso para os filhos. Outra questão é a religião, que as vezes se manifesta de maneira muito forte. Sexualidade é uma temática que, para conseguirmos fazer um bom trabalho, temos que pensar muito bem na forma que vamos fazer isso, porque é um assunto, ao meu ponto de vista, bastante delicado. (Professora F)

Em uma das entrevistas, quando a professora foi questionada sobre as dificuldades ela relatou que encontrou bastante resistência por parte da direção da escola, sobre as maneiras e formas de abordar o tema, colocando assim certo limite ao fazer docente. Isso mostra que a escola também se encontra despreparada para falar sobre sexualidade e que de alguma forma 
acredita estar incentivando os alunos sobre algumas questões relacionadas à temática, como por exemplo, dar início a uma vida sexual precoce.

Entretanto, dentro de uma mesma escola, os professores possuem formas de trabalhar e visões sobre sexualidade diferentes um dos outros. Na entrevista com a professora A foi abstraída a seguinte colocação: "Eu sou uma professora que não tenho problema nenhum em tratar sobre qualquer tipo de assunto com meus alunos, [...] abordo através de brincadeiras, dependendo da idade deles, da série e do entendimento que eles demonstram sobre o assunto, eu vou esclarecendo algumas dúvidas".

Ao trabalhar sexualidade em sala de aula, as dificuldades que aparecem nem sempre são as mesmas entre os professores. Em alguns casos, uma das dificuldades é em relação à falta de materiais didáticos. De acordo com algumas professoras entrevistadas, essa é uma realidade presente nas escolas.

[...] Aqui na escola temos pouco material, quase nada, se utiliza mais o livro e esse aborda mais o corpo humano e não todas as outras questões que envolvem a sexualidade. (Professora D)

[...] Não temos material didático para trabalhar, a gente se vira, confecciona as vezes junto com os alunos, mas da escola não temos esse apoio. (Professora E)

O material didático é considerado a ligação entre as palavras e a realidade concreta. Sua principal função é auxiliar o aluno a pensar, possibilitando o desenvolvimento de sua imaginação e de sua capacidade de estabelecer analogias. É aproximar o aluno da realidade e auxiliá-lo a tirar dela o que contribui para sua aprendizagem (Schmitz, 1993).

A importância dos materiais didáticos para trabalhar a temática fica evidenciada quando notamos que uma das dificuldades apontadas pelas professoras e que restringe o estudo em sala de aula é a falta dessas ferramentas. Pedroso (1999), em pesquisas realizadas com professores de ciências do Ensino Fundamental, constatou que para os docentes a utilização de recursos didáticos é um dos aspectos principais para viabilizar o trabalho sobre educação sexual. Porém, segundo os professores, os materiais presentes nas escolas são insuficientes e pouco diversificados e por vezes não existem. Essa necessidade de materiais mencionados pelos professores, provavelmente, deve-se ao fato do que abordar o tema sexualidade requer, além de diálogos e discussões, também algo que aproxime o aluno da realidade, tornando a aula mais proveitosa e dinâmica. Essa reflexão feita pelo autor citado vai de encontro com o relato feito pela professora D "É muito importante, todo e qualquer material que sirva de apoio para as aulas é de grande valor, pois as aulas rendem e produzem mais, além do aprendizado que é diferenciado".

Analisando os resultados de maneira geral pode-se afirmar que os materiais didáticos para educação sexual no Ensino Fundamental são necessários e importantes. É um recurso indispensável que precisa estar disponível nas escolas e dependerá da habilidade do professor selecionar, valorizar e utilizar os recursos de maneira adequada e produtiva. A seleção dos materiais deve levar em consideração o aluno ao qual será destinado (faixa etária, interesses, objetivos e os conteúdos a serem aprendidos), portanto, essas ferramentas pedagógicas servem para facilitar e tornar a aprendizagem integrada, dinâmica e lúdica.

\section{Considerações Finais}

Os resultados demonstraram que todas as professoras entrevistadas consideram importante ações de educação sexual na escola, sendo este um lugar favorável à implementação de estudos voltados a essa temática. Porém, a sexualidade ainda vem sendo discutida de forma insuficiente no contexto escolar, por isso o que se espera é que a educação sexual seja transmitida de forma com que aproxime os estudantes da sua realidade, ampliando a sua visão de mundo, ajudando-o a refletir e compreender 
da melhor maneira os assuntos relacionados à temática, levando em conta a subjetividade e a fase do desenvolvimento dos alunos, respeitando as diversidades e formando-os para viver sua sexualidade de forma saudável e responsável.

Em relação ao desenvolvimento da temática, os participantes da pesquisa relataram que ao trabalhar o tema em sala de aula sentem-se despreparados e inseguros, pois em sua formação, tanto a inicial quanto na continuada, não tiveram um preparo de como discutir com os alunos a sexualidade, não sabem quais os termos usar. Em relação à formação dos professores, podese dizer que a educação ainda trata a sexualidade como um "tabu" e essa lacuna ainda existe tanto na escola, nas famílias, na sociedade e também nas políticas educacionais.

Também se percebe que os PCNs e a BNCC trazem em sua estrutura diversas atribuições sobre educação sexual, porém as Diretrizes Curriculares Nacionais para o Ensino Fundamental em nenhum momento dentro dos componentes curriculares trazem assuntos relacionados à sexualidade, apenas aborda as questões biológicas do corpo humano que faz parte do currículo. Isso demostra que as políticas públicas nem sempre valorizam a temática e sua importância tanto para a vida dos alunos, quanto para a preparação dos docentes. Com isso é possível entender que a proposta do PCNs não contempla a realidade estudada, então sugere-se novos olhares acerca da legislação e prática para que de fato se consolide uma educação sexual pautada na humanidade e em informações que instrumentalizem e forneçam segurança ao professor ao abordar o assunto.

Todavia, ao ressaltar a sexualidade como um processo de construção cultural e histórica, é perceptível que as escolas ainda possuem carência em profissionais capacitados para lidar com tal realidade, pois, mesmo com todo avanço, há desafios a serem resolvidos para que a educação sexual seja vista como importante e indispensável, pois esta é inerente na vida de todos os sujeitos.

De acordo com os resultados dessa pesquisa e dos relatos feitos pelas professoras que fizeram parte deste estudo, é necessário ressaltar novamente a importância de uma formação inicial e continuada no processo de preparação dos docentes, pois os professores estão enfrentando em sala de aula alunos que vivem em uma era tecnológica bastante avançada e estão muito curiosos para entender melhor assuntos que veem na mídia, e a escola é vista como um espaço de interação que possibilita os estudantes acesso as informações, e o professor é considerado o mediador, e que está ali para esclarecer, instruir e orientar os alunos sobre determinados assuntos.

A sexualidade por ser um tema delicado não tem sido discutida de maneira suficiente, pois ainda existe muitas barreiras impostas pela sociedade, pelas famílias e cultura, os docentes se sentem despreparados e inseguros ao tratar do assunto, para mudar essa situação e à tornar satisfatória, a educação deve evoluir de acordo com a realidade em que se vive hoje, capacitando os professores para que esses possam realizar seu trabalho de forma efetiva e significativa na escola.

Com isso, sugere-se para os novos estudos levando em consideração as especificações da formação docente para se trabalhar o tema sexualidade, uma revisão nas propostas de currículo, principalmente para os cursos que formam professores (licenciatura), com o objetivo de garantir que a temática seja incluída, considerando à quase total ausência de tais discussões na formação inicial.

\section{Referências}

Altmann, H. (2003). Orientação Sexual em uma escola: recortes de corpos e de gênero. Cadernos Pagu, 21, 281-315.

Aquino, C., \& Martelli, A.C. (2012). Escola e educação sexual: uma relação necessária. IX Seminário de Pesquisa em Educação da Região Sul - ANPEDSUL, Caxias do Sul - RS.

Bardin, L. (2011). Análise de Conteúdos. Lisboa, 70.

Beraldo, F. M. N. (2003). Sexualidade e escola: um espaço de intervenção. Scielo, Campinas7. <http://scielo.br/scielo.php?pid=S141385572003000100012\&script=sci_arttext> 
Braga, E. R. M. (2006). Sexualidade infantil: a importância da formação de professores(as) na questão de gênero. In: Educação no século XXI: Múltiplos desafios. Maringá: Eduem.

Brasil. (1998). Ministério da Educação. Parâmetros curriculares nacionais. Terceiro e quarto anos do ensino fundamental. Introdução aos parâmetros curriculares nacionais. Brasília: MEÇ.

Brasil. (1998). Ministério da Educação. Parâmetros curriculares nacionais. Orientação Sexual. MEC.

Burchard, C. P., Barbosa, L. U., \& Copetti, J. (2020). Prática docente acerca do tema sexualidade: uma revisão sistemática. Research, Society and Development. 9(7). https://rsdjournal.org/index.php/rsd/article/view/4993/4246

César, M. R. A. (2009). Gênero, sexualidade e educação: notas para uma “epistemologia”. Revista Educar, 35, 37-51.

Figueiró, M. N. D. (2009). Educação sexual: múltiplos temas, compromisso comum. (org.) Educação Sexual: como ensinar no espaço da escola. Londrina: UEL, 190 .

Foucault, M. (1977). História da Sexualidade I: a vontade de saber. Edições Graal.

Gaspar, T. (2006). Comportamentos Sexuais, conhecimentos e atitudes face ao HIV/SIDA em adolescentes migrantes. Psicologia, Saúde e Doenças. 7(2), 299-316.

Guimarães, I. (1995). Educação Sexual na escola: mito e realidade. Mercado de Letras.

Jardim D. P., \& Brêtas J. R. S. (2006). Orientação sexual na escola: a concepção dos professores de Jandira - SP. Revista Brasileira de Enfermagem, 59(2), $157-162$.

Maistro, V. I. A. (2006). Projetos de orientação sexual na escola: seus limites e suas possibilidades. Londrina: Universidade Estadual de Londrina.

Minayo, M. C. S. (1994). Pesquisa Social: teoria, método e criatividade. Vozes, 21-22.

Nóvoa, A. (2018). Desafios do trabalho do professor no mundo contemporâneo. Palestra SIMPRO-SP - Sindicato dos professores de São Paulo. <http://www.sinprosp.org.br/arquivos/novoa/livreto_novoa.pdf.

Nóvoa, A. (2009). Professores: imagens do futuro presente. Educa.

Nunes, C. A. (1997). Desvendando a sexualidade. 3. Papirus.

Paula, J. A., \& Santos, L. M. (2012). Sexualidade na escola: a necessidade de superar tabus. Formação continuada. Lambarí d’Oeste-MT.

Pedroso, A. G. (1999). Materiais didáticos para orientação sexual em escolas estaduais de Botucatu. (Monografia apresentada ao departamento de Educação do Instituto de Biociências, UNESP, Campus de Botucatu, para obtenção do título de Licenciado em Ciências Biológicas).

Quirino, J. S. (2003). Sexualidade na escola: encaminhamentos metodológicos na perspectiva dos professores de Ciências. 2003. <http://www.uel.br/pos/mecem/arquivos_pdf/QUIRINO.pdf>

Rodrigues, A. R. F., \& Salles, G. D. (2016). Educação Sexual, Gênero e Diversidade Sexual: Formação de professoras e alunas multiplicadoras como Metodologia de Ensino. Anais II Simpósio Gênero e Políticas Públicas. Universidade Estadual de Londrina, GT6-Gênero e Educação.

Santos, A. L. R. dos., Assis, A. L. R., Marra, B. P., \& Oliveira, M. E. P. de. (2021). Educação Sexual no ambiente escolar. Monografia apresentada como requisito parcial para obtenção do título de Licenciatura em Pedagogia. Centro Universitário UnaBetim. https://repositorio.animaeducacao.com.br/bitstream/ANIMA/14452/7/EDUCA\%C3\%87\%C3\%83O\%20SEXUAL\%20NO\%20AMBIENTE\%20ESCOLAR.pd $\mathrm{f}$

Schindhelm, V. G. (2011). A Sexualidade na Educação Infantil. Revista Aleph Infâncias. (5)16.

Schmitz, E. (1993). Fundamentos da Didática. 7. 175. UNISINOS.

Silva, L. M. M., \& Santos, S. P. (2011). Sexualidade e Formação Docente: representações de futuros professores/as de Ciências e Biologia. VII Encontro Nacional de Pesquisa em Educação em Ciências. 